\title{
PTU-127 $九$ GASTROENTEROLOGY TRAINING IN 2010: RESULTS FROM THE TIG/BSG NATIONAL TRAINING SURVEY
}

doi:10.1136/gut.2011.239301.255

A Haycock, * A Ignjatovic, C Lamb, J Neale, P Flanagan, J Hender, M Mottershead, T Valliani, V Patel, J Russell; Trainees in Gastroenterology (TiG) TiG, London, UK

Introduction The last national survey of gastroenterology trainees in 2008 revealed that although the majority of trainees felt that their training was satisfactory, there was significant variation across the country. Overall, lack of adequate training in nutrition was considered the most concerning area. Educational supervision and personal development plans were not being widely utilised.

Methods An invitation to complete a web-based questionnaire was emailed to all trainees and data was collected in Febuary 2010. For comparison, results from the 2008 survey are given in square brackets where applicable.

Results Training positions $10.1 \%$ of trainees were in specialist hepatology posts. $24.2 \%$ were in OOPE, with $19.6 \%$ having already done OOPE (85.5\% for research).

General gastroenterology Nutrition is still the area the majority of trainees do not think they will attain competence in, and it was worse than in 2008. 25\% felt that they had not had and were unlikely to get a period of formal nutrition training as a registrar. $64 \%$ did not feel that they would be confident to run a nutrition team after attaining CCST.

Specialisation $73 \%$ SpRs want to subspecialise but many were not certain if there were adequate training opportunities in their region to attain specialist competence. $74 \%(81 \%)$ would be prepared to commute and $47 \%(50 \%)$ to move permanently to another area to obtain better training in a subspeciality.

Endoscopy 54\% (40\%) now get formative DOPS filled in regularly. $21.4 \%(16.9 \%)$ are not very or very unsatisfied with their endoscopy training. Most comments were due to lack 
of training lists, particularly for colonoscopy and therapeutic techniques.

Study leave $68 \%$ (59\%) never or only occasionally are able to take half day study leave per week.

Training/Education $65.8 \%(58.2 \%)$ of training programmes are now on a rolling schedule. $97.1 \%(95.4 \%)$ now have an educational supervisor. $24.8 \%(22.8 \%)$ of $\mathrm{SpRs}$ intend to sit the SCE. $29.5 \%$ (50.8\%) do not have a PDP (Personal Development Plan)

General $11.8 \%$ (18\%) posts non-EWTD compliant. $72.3 \%$ (78.8\%) believe training affected by EWTD with 100\% (95.3\%) saying it has been impaired (38.7\% greatly impaired).

Workforce planning Given the choice, $44.6 \%$ (48.9\%) would choose to practice gen med. $75.3 \%$ (67.7\%) would not consider a job in acute medicine with gastroenterology. $19.6 \%$ wish to work part time as a consultant.

Conclusion More trainees have formal educational support and are using assessment tools regularly than 2 years ago. However, the issues that were of concern in the last survey remain problems, and trainees feel that in some cases, in particular the provision of nutrition training, things may actually have become worse.

Competing interests None.

Keywords training. 